\title{
Cardiac rehabilitation uptake following myocardial infarction: cross-sectional study in primary care
}

\author{
Margaret E Cupples, Mark A Tully, Martin Dempster, Mairead Corrigan, \\ Damian O McCall and Bernadette Downey
}

\author{
ABSTRACT

\section{Background} \\ Policies suggest that primary care should be more \\ involved in delivering cardiac rehabilitation. However, \\ there is a lack of information about what is known in \\ primary care regarding patients' invitation or \\ attendance. \\ Aim \\ To determine, within primary care, how many patients \\ are invited to and attend rehabilitation after myocardial \\ infarction (MI), examine sociodemographic factors \\ related to invitation, and compare quality of life \\ between those who do and do not attend.

\section{Design of study} \\ Review of primary care paper and computer records; \\ cross-sectional questionnaire. \\ Setting \\ Northern Ireland general practices (38); stratified \\ sample, based on practice size and health board area. \\ Method \\ Patients, identified from primary care records, \\ 12-16 weeks after a confirmed diagnosis of MI, were \\ posted questionnaires, including a validated MacNew \\ post-MI quality-of-life questionnaire. Practices returned \\ anonymised data for non-responders. \\ Results \\ Information about rehabilitation was available for 332 \\ of the 432 patients identified (76.9\%): 162 (37.5\%) \\ returned questionnaires. Of the total sample, $54.4 \%$ \\ (235/432) were invited and 37.0\% (160/432) attended; \\ of those invited, $68.1 \%(160 / 235)$ attended. Invited \\ patients were younger than those not invited (mean \\ age 63 years [standard deviation \{SD\} 16] versus \\ 68.5 years [SD 16]); mean difference 5.5 years $(95 \%$ \\ confidence interval $[\mathrm{Cl}]=1.7$ to 9.3 ). Among \\ questionnaire responders, those who attended were \\ younger and reported better emotional, physical, and \\ social functioning than non-attenders $(P=0.01$; mean \\ differences $0.44(95 \% \mathrm{Cl}=0.11$ to 0.77$), 0.48(95 \% \mathrm{Cl}$ \\ $=0.10$ to 0.85$)$ and $0.54(95 \% \mathrm{Cl}=0.15$ to 0.94$)$ \\ respectively).

\section{Conclusion} \\ Innovative strategies are needed to improve cardiac \\ rehabilitation uptake, integration of hospital and \\ primary care services, and healthcare professionals' \\ awareness of patients' potential for health gain after \\ MI.

\section{Keywords} \\ cardiac rehabilitation; family practice; primary health \\ care; rehabilitation.
}

\section{INTRODUCTION}

The importance of cardiac rehabilitation has been established, ${ }^{1}$ yet many potentially eligible patients with coronary heart disease (CHD) do not attend. ${ }^{2,3}$ Recent guidelines identify rehabilitation as an essential component in patients' care following myocardial infarction (MI) and emphasise that integrated service provision is needed, recommending that rehabilitation plans should be included in every patient's hospital discharge summary. ${ }^{4}$ Primary care is attributed a key role in managing patients with $\mathrm{CHD},{ }^{5}$ but little information is available about what is known in primary care about their rehabilitation invitation and attendance.

Most rehabilitation programmes are provided from a hospital base, but evidence that home-based programmes produce similar outcomes is increasing. ${ }^{6,7}$ Inadequate funding, ${ }^{2,8,9}$ and acknowledgement that many patients prefer homebased programmes, ${ }^{10}$ indicate a need for more active primary care involvement in service delivery. Information about referral and the sociodemographic characteristics and quality of life of individuals who are not invited to current rehabilitation services is incomplete. ${ }^{2}$

ME Cupples, MD, FRCGP, clinical reader; MA Tully, PhD, postdoctoral research fellow, Centre of Excellence for Public Health (NI); M Dempster, PhD, research co-ordinator, School of Psychology; M Corrigan, PhD, lecturer; DO McCall, MD, research fellow, School of Medicine, Dentistry and Biomedical Science, Queen's University Belfast, Northern Ireland. B Downey, MSc, senior cardiac nurse, Mater Hospital, Belfast Acute and Community Trust, Belfast, Northern Ireland.

Address for correspondence

Margaret E Cupples, Department of General Practice and Primary Care, Dunluce Health Centre, 1 Dunluce Avenue, Belfast BT9 7HR. E-mail: m.cupples@qub.ac.uk

Submitted: 24 August 2009; Editor's response: 26 October 2009; final acceptance: 7 January 2010.

(c)British Journal of General Practice 2010; 60: 431-435. 


\section{How this fits in}

Cardiac rehabilitation is a cost-effective treatment but many potentially eligible patients do not attend. Primary care is identified as having a key role in

improving uptake, yet little is known regarding its knowledge of patients'

invitation and attendance. Information relating to rehabilitation was found in

primary care for $77 \%$ of patients after myocardial infarction and indicated that

$37 \%$ attended: those who attended were younger, with a better quality of life.

Innovative strategies are needed to improve systems integrating hospital and

primary care services and to maximise patients' potential for health gain.

This study aimed to determine, from within primary care, how many patients, after a MI, are invited to and attend rehabilitation, to examine sociodemographic characteristics associated with invitation, and to compare quality of life between those who do and do not attend.

\section{METHOD}

\section{Participants}

Based on geographical location (health board area) and practice size, a stratified sample of 38 general practices in Northern Ireland (NI) was identified. Their combined list (236 430) had age and sex distributions similar to the $\mathrm{NI}$ population: $49.7 \%$ were males (117 393/236 430). Practices used a prespecified computer search strategy to identify patients with $\mathrm{Ml}$ or acute coronary syndrome, and repeated this every 2 weeks (May 2005 to February 2007). Both diagnoses were included because pilot work identified inconsistencies between cardiologists in attributing these diagnoses. ${ }^{11}$ Patients with recorded evidence of electrocardiogram changes or cardiac biomarkers supporting the diagnosis of an acute event 12-16 weeks previously were invited to participate.

\section{Data collection}

Potential participants were posted questionnaires and a reply slip indicating consent for researchers to access their medical records. Data collected related to sociodemographic information, rehabilitation invitation and attendance, reasons for non-attendance, comorbidities, and quality of life (validated MacNew post-MI questionnaire). ${ }^{12}$

Non-responders were telephoned after 2 weeks, reminded of the invitation, and asked about rehabilitation invitation and attendance. If no contact was made, staff searched paper and computer records and returned anonymous data regarding rehabilitation, age, sex, and postcode, from which measures of socioeconomic status were derived (Multiple Deprivation Measure [MDM]: higher values indicate less deprivation). If no information was found, records were searched up to 6 months later.

\section{Statistical analysis}

It was estimated that 76 in each group would allow detection of a $10 \%$ difference between attenders and non-attenders in physical, emotional, and social functioning quality-of-life scores with $0.05 \alpha$ and $80 \%$ power. This was derived from piloting the MacNew post-MI questionnaire in 30 patients and finding that 0.41 (relating to physical functioning) was the smallest difference observed between attenders and non-attenders. The study population was chosen to allow recruitment of $160 \mathrm{Ml}$ survivors within the study period, estimating $0.2 \%$ annual $\mathrm{Ml}$ incidence, $50 \%$ survival, and $40 \%$ response rate.

Using SPSS (version 14.0), categorical data were compared between those who were and were not invited, and between those who did and did not attend, using $\chi^{2}$ tests; deprivation scores were compared by Mann-Whitney tests, and quality-oflife measures by $t$ tests.

\section{RESULTS}

\section{Demography of sample}

Of 432 individuals identified, invitation data were obtained for $332(76.9 \%)$ and attendance data for 330 (76.4\%); 37.5\% (162/432) responded to the questionnaire. Questionnaire responders and nonresponders did not differ significantly in mean age (63.6 years [standard deviation \{SD 18.5 , versus 66.3 [SD 13.7]), sex distribution (75.3\% male [122/162] versus $70.0 \%$ [189/270]), or deprivation (median MDM 414.5 versus 364.0).

\section{Invitation}

Data indicated that, overall, 54.4\% (235/432) were invited to rehabilitation, $22.5 \%(97 / 432)$ were not: no information was available for $23.1 \%$ (100/432) (Figure 1). Among those with invitation data, 70.8\% (235/332) were invited: those invited were younger than those who were not (Table 1) but their sex distribution and socioeconomic status were similar. Questionnaire responses showed that the odds of retired people being invited were less, compared to those who were not retired (Table 2).

\section{Attendance}

Overall, data indicated that $37.0 \%$ attended (160/432) but no attendance information was available for 102 (23.6\%). Comparing 'attenders' with 'non-attenders' (including those not invited), showed that attenders were younger (Table 1). Of those invited, 68.1\% (160/235) attended.

Among questionnaire responders who were invited, $71.3 \%$ (82/115) attended (Table 2). Home 


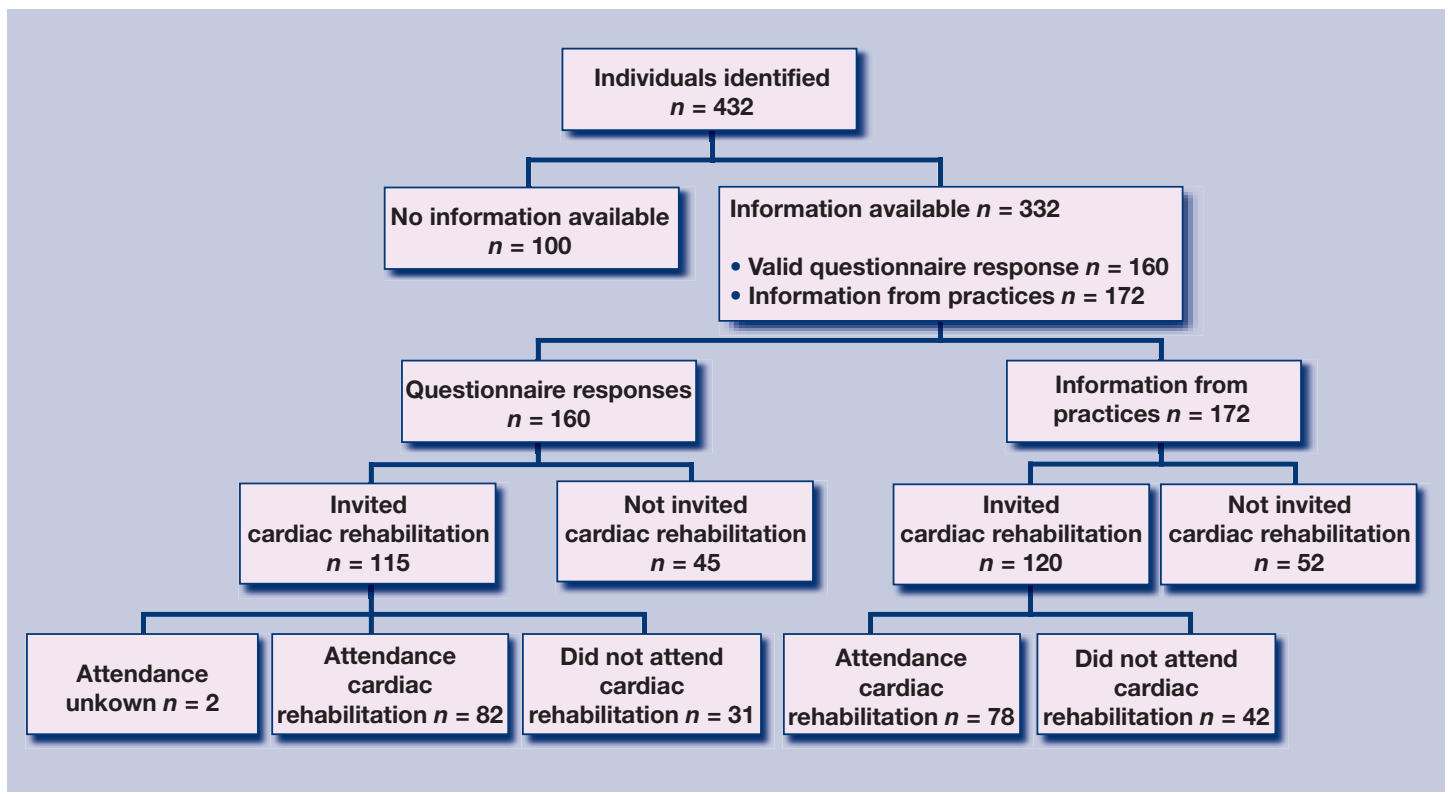

Figure 1. Flow of participants through the study.

owners were more likely to attend than non-home owners but no other sociodemographic differences were found.

Further analysis, involving invited participants only, showed attenders' deprivation score was higher than non-attenders' (median 426.5 versus 250.5, $P=0.04$ ).

\section{Quality of life}

Comparing those who attended with those who did not, including those who were not invited, showed that attenders had better emotional, physical, and social functioning, reflecting a better quality of life (Table 2).

\section{DISCUSSION}

\section{Summary of main findings}

This study found that no information about cardiac rehabilitation after $\mathrm{Ml}$ was held in primary care for $23 \%$ of patients. Overall, data indicated that $37 \%$ attended: 54\% were invited and two-thirds of these attended, but older patients were less likely to be invited and attend. Those who attended had a better quality of life.

\section{Strengths and limitations of the study}

The study findings have external validity: participants were similar to non-participants in terms of age, sex, and socioeconomic status and the participating practices were representative of the general practices in Northern Ireland. Every participant's primary care record contained a hospital discharge summary confirming their diagnosis, all $\mathrm{NI}$ hospitals contributed to management of some participants, and ample time was allowed for information transfer between services.

Absence of information relating to cardiac rehabilitation is likely to reflect non-invitation and non-attendance. It is recognised that the accuracy

\section{Table 1. Demographic characteristics of post-MI patients with cardiac rehabilitation invitation and attendance information (combined questionnaire and anonymous data).}

\begin{tabular}{|c|c|c|c|c|c|c|c|c|}
\hline Characteristics & $\begin{array}{l}\text { Invited }^{\mathrm{a}} \\
(n=235)\end{array}$ & $\begin{array}{l}\text { Not invited }^{\mathrm{a}} \\
\quad(n=97)\end{array}$ & $P$-value & $\begin{array}{l}\text { Difference } \\
(95 \% \mathrm{Cl})\end{array}$ & $\begin{array}{l}\text { Attenders }^{a} \\
(n=160)\end{array}$ & $\begin{array}{c}\text { Non-attenders } \\
\quad(n=170)\end{array}$ & $P$-value & $\begin{array}{c}\text { Difference } \\
(95 \% \mathrm{Cl})\end{array}$ \\
\hline $\begin{array}{l}\text { Mean age, years } \\
(\mathrm{SD})\end{array}$ & $\begin{array}{c}62.9 \\
(16.2) \\
\end{array}$ & $\begin{array}{c}68.5 \\
(15.3) \\
\end{array}$ & 0.004 & $\begin{array}{c}5.5 \\
(1.8 \text { to } 9.3)^{\mathrm{b}}\end{array}$ & $\begin{array}{c}61.967 .0 \\
(15.4)\end{array}$ & $(16.5)$ & 0.003 & $\begin{array}{c}5.2 \\
(1.7 \text { to } 8.6)^{t}\end{array}$ \\
\hline \multicolumn{9}{|l|}{ Sex } \\
\hline $\begin{array}{c}\text { Male, } n \\
(\%)\end{array}$ & $\begin{array}{c}171 \\
(72.8 \%)\end{array}$ & $\begin{array}{c}64 \\
(27.2 \%)\end{array}$ & 0.27 & $\begin{array}{c}1.38 \\
(0.8 \text { to } 2.3)^{c}\end{array}$ & $\begin{array}{c}116 \\
(49.4 \%)\end{array}$ & $\begin{array}{c}119 \\
(50.6 \%)\end{array}$ & 0.70 & $\begin{array}{c}1.1 \\
(0.7 \text { to } 1.8)\end{array}$ \\
\hline $\begin{array}{l}\text { Female, } n \\
(\%)\end{array}$ & $\begin{array}{c}64 \\
(66 \%)\end{array}$ & $\begin{array}{c}33 \\
(34 \%)\end{array}$ & & & $\begin{array}{c}44 \\
(46.3 \%)\end{array}$ & $\begin{array}{c}51 \\
(53.7 \%)\end{array}$ & & \\
\hline Median MDM & 369 & 369 & 0.69 & - & 427 & 364 & 0.19 & - \\
\hline
\end{tabular}

aInvitation data relate to 332 individuals; attendance data relate to 330 (two data returns invalid). ${ }^{b}$ Mean difference. ${ }^{\circ}$ Odds ratio (of male being invited/attending compared to female being invited/attending). MDM = Multiple Deprivation Measure. $M I=$ myocardial infarction. 


\begin{tabular}{|c|c|c|c|c|c|c|c|c|}
\hline Characteristics & $\begin{array}{l}\text { Invited }^{a} \\
(n=115)\end{array}$ & $\begin{array}{l}\text { Not invited } \\
\quad(n=45)\end{array}$ & $P$-value & $\begin{array}{l}\text { Odds ratio } \\
(95 \% \mathrm{Cl})\end{array}$ & $\begin{array}{l}\text { Attenders }^{\mathrm{b}} \\
(n=82)\end{array}$ & $\begin{array}{l}\text { Non-attenders }{ }^{\mathrm{b}} \\
\quad(n=76)\end{array}$ & $P$-value & $\begin{array}{l}\text { Odds ratio } \\
(95 \% \mathrm{Cl})\end{array}$ \\
\hline Retired, $n(\%)$ & $\begin{array}{c}52 \\
(62.7) \\
\end{array}$ & $\begin{array}{c}31 \\
(37.3) \\
\end{array}$ & 0.01 & $\begin{array}{c}0.4 \\
(0.2 \text { to } 0.8)\end{array}$ & $\begin{array}{c}40 \\
(48.2) \\
\end{array}$ & $\begin{array}{c}43 \\
(51.8) \\
\end{array}$ & 0.41 & $\begin{array}{c}0.7 \\
(0.4 \text { to } 1.4)\end{array}$ \\
\hline Employed, $n(\%)$ & $\begin{array}{c}38 \\
(77.6) \\
\end{array}$ & $\begin{array}{c}11 \\
(22.4) \\
\end{array}$ & 0.39 & $\begin{array}{c}1.5 \\
(0.7 \text { to } 3.3) \\
\end{array}$ & $\begin{array}{c}30 \\
(62.5) \\
\end{array}$ & $\begin{array}{c}18 \\
(37.5) \\
\end{array}$ & 0.11 & $\begin{array}{c}1.9 \\
(0.9 \text { to } 3.7) \\
\end{array}$ \\
\hline \multicolumn{9}{|l|}{ Marital status ${ }^{d}$} \\
\hline $\begin{array}{l}\text { Married/ living with } \\
\text { partner, } n(\%)\end{array}$ & $\begin{array}{c}83 \\
(74.8)\end{array}$ & $\begin{array}{c}28 \\
(25.2)\end{array}$ & 0.20 & 1.7 & $\begin{array}{c}59 \\
(53.6)\end{array}$ & $\begin{array}{c}51 \\
(46.4)\end{array}$ & 0.46 & 1.4 \\
\hline Other status, $n(\%)$ & $\begin{array}{l}29 \\
(63)\end{array}$ & $\begin{array}{l}17 \\
(37)\end{array}$ & & $(0.8 \text { to } 3.6)^{9}$ & $\begin{array}{c}21 \\
(45.7) \\
\end{array}$ & $\begin{array}{c}25 \\
(54.3) \\
\end{array}$ & & $(0.7 \text { to } 2.8)^{h}$ \\
\hline Car ownership, $n$ (\%) & $\begin{array}{c}93 \\
(74.4)\end{array}$ & $\begin{array}{c}32 \\
(25.6)\end{array}$ & 0.26 & $\begin{array}{c}1.7 \\
(0.8 \text { to } 3.8)\end{array}$ & $\begin{array}{c}68 \\
(54.8)\end{array}$ & $\begin{array}{c}56 \\
(45.2)\end{array}$ & 0.22 & $\begin{array}{c}1.7 \\
(0.8 \text { to } 3.7)\end{array}$ \\
\hline Home ownership, ${ }^{e} n$ (\%) & $\begin{array}{l}8537 \\
(69.7) \\
\end{array}$ & $(30.3)$ & 0.37 & $\begin{array}{c}0.6 \\
(0.2 \text { to } 1.5)\end{array}$ & $\begin{array}{c}65 \\
(53.7) \\
\end{array}$ & $\begin{array}{c}56 \\
(46.3) \\
\end{array}$ & 0.34 & $\begin{array}{c}1.6 \\
(0.7 \text { to } 3.4)\end{array}$ \\
\hline $\begin{array}{l}\text { Median distance from } \\
\text { rehabilitation centre, milest }\end{array}$ & 6 & 6.5 & 0.25 & & 6 & 5 & 0.76 & \\
\hline $\begin{array}{l}\text { Illness preventing exercise } \\
\text { (self-report), }{ }^{9} n(\%)\end{array}$ & $\begin{array}{c}46 \\
(65.7) \\
\end{array}$ & $\begin{array}{c}24 \\
(34.3) \\
\end{array}$ & 0.17 & $\begin{array}{c}0.6 \\
(0.3 \text { to } 1.2)\end{array}$ & $\begin{array}{c}29 \\
(42.6) \\
\end{array}$ & $\begin{array}{c}39 \\
(57.4) \\
\end{array}$ & 0.05 & $\begin{array}{c}0.5 \\
(0.3 \text { to } 1.0)\end{array}$ \\
\hline \multicolumn{3}{|l|}{ Quality of life', mean score (SD) } & & $\begin{array}{c}\text { Mean } \\
\text { difference } \\
(95 \% \mathrm{Cl}) \\
\end{array}$ & & & & $\begin{array}{c}\text { Mean } \\
\text { difference } \\
(95 \% \mathrm{Cl}) \\
\end{array}$ \\
\hline Emotional functioning & $\begin{array}{r}4.89 \\
(1.07) \\
\end{array}$ & $\begin{array}{r}4.59 \\
(1.00)\end{array}$ & 0.11 & $\begin{array}{c}0.30 \\
(-0.07 \text { to } 0.67) \\
\end{array}$ & $\begin{array}{c}5.02 \\
(1.06) \\
\end{array}$ & $\begin{array}{c}4.59 \\
(1.01) \\
\end{array}$ & 0.01 & $\begin{array}{c}0.44 \\
(0.11 \text { to } 0.77) \\
\end{array}$ \\
\hline Physical functioning & $\begin{array}{r}5.06 \\
(1.13) \\
\end{array}$ & $\begin{array}{c}4.42 \\
(1.29) \\
\end{array}$ & 0.003 & $\begin{array}{c}0.64 \\
(0.23 \text { to } 1.06) \\
\end{array}$ & $\begin{array}{r}5.11 \\
(1.06) \\
\end{array}$ & $\begin{array}{r}4.64 \\
(1.29) \\
\end{array}$ & 0.01 & $\begin{array}{c}0.48 \\
(0.10 \text { to } 0.85) \\
\end{array}$ \\
\hline Social functioning & $\begin{array}{c}5.24 \\
(1.24)\end{array}$ & $\begin{array}{l}4.61 \\
(1.29)\end{array}$ & 0.006 & $\begin{array}{c}0.62 \\
(0.18 \text { to } 1.06)\end{array}$ & $\begin{array}{c}5.33 \\
(1.25)\end{array}$ & $\begin{array}{c}4.78 \\
(1.24)\end{array}$ & 0.01 & $\begin{array}{c}0.54 \\
(0.15 \text { to } 0.94)\end{array}$ \\
\hline
\end{tabular}

aInvitation status unknown for two responders. ${ }^{b}$ Attendance status unknown for four responders. 'Odds ratio (OR) of being invited to not being invited/attending to not attending for each characteristic). ${ }^{\circ}$ Valid responses for invitation data $=157$; for attendance data $=156$. ${ }^{\circ}$ Four responders did not answer. ${ }^{f} 16$ responders did not answer. ${ }^{9}$ Seven responders did not answer. ${ }^{n} \mathrm{OR}$ of being married/with partner and invited/attending to other marital status being invited/attending. MacNew post-MI questionnaire, with five invalid responses excluded.

of all self-reported information was not checked. However, a quality check was performed on a random $10 \%$ sample of the questionnaire data and this indicated that the variation between selfreported and recorded information was small.

\section{Comparison with existing literature}

Previous studies found that younger, male,,$^{13,14}$ and married ${ }^{14}$ individuals were more likely to be invited to rehabilitation. However, no evidence was found in this study of invitation bias relating to sex or marital status. The study finding that $68 \%$ of those invited attended compares with recent audit data that approximately $77 \%$ of invited patients attend. ${ }^{2}$

A recent Canadian study reported that less than half of primary care physicians received information about patients' progress in cardiac rehabilitation. ${ }^{15}$ The present study has also identified a communication gap between services. While this study preceded the launch of regional guidelines, ${ }^{16}$ anecdotes suggest that physicians in both primary care and hospital could attribute more importance to rehabilitation. Research indicates that patients who perceive their physician considers rehabilitation important are more likely to attend. ${ }^{17,18}$

\section{Implications for clinical practice and future research}

Previous trials reporting benefits of cardiac rehabilitation for quality of life showed small effect sizes, with varied outcome measures and methodological quality. ${ }^{19,20}$ The present finding of better quality of life among attenders may suggest that those with better quality of life are more likely to attend but may also indicate that benefit is derived from attendance. Regular reviews, ${ }^{21,22}$ and other organisational changes in general practice, ${ }^{23}$ have led to improved provision of secondary prevention. However, this is not necessarily associated with better quality of life. ${ }^{24}$ There is a need for more holistic care of patients following MI.

Strategies are needed to address gaps in systems, communications, and coordination of services. The responsibility for developing these 
must be shared between hospital and primary care. Further exploration of strategies to engage professionals and patients in rehabilitation and translate policy into practice is warranted, to minimise gaps in service provision and maximise patients' potential for health.

\section{Funding body}

The research was funded by the Research and Development Office (Northern Ireland). Margaret E Cupples and Mark A Tully are co-funded by the Centre of Excellence for Public Health (Northern Ireland), a UKCRC Public Health Research Centre of Excellence. Funding from the British Heart Foundation, Cancer Research UK, Economic and Social Research Council, Medical Research Council, Research and Development Office for the Northern Ireland Health and Social Services, and the Wellcome Trust, under the auspices of the UK Clinical Research Collaboration, is gratefully acknowledged.

\section{Ethics committee}

Queen's University Belfast Ethics Committee gave the study ethical approval (Ref No. 362/03, November 2003).

\section{Competing interests}

The authors have stated that there are none.

\section{Acknowledgements}

We wish to thank all participating practices, their staff, and patients who contributed to the data collection, and Professor lan Young, Dr Gavin Dalzell, Dr Barry Kelly, and Dr Noleen McCorry for their help and advice.

\section{Discuss this article}

Contribute and read comments about this article on the Discussion Forum: http://www.rcgp.org.uk/bjgp-discuss

\section{REFERENCES}

1. Bethell H, Lewin R, Dalal H. Cardiac rehabilitation in the United Kingdom. Heart 2009; 95(4): 271-275.

2. British Heart Foundation. The National Audit of Cardiac Rehabilitation Annual Statistical Report 2008. http://www.bhf.org.uk/publications/view_publication.aspx?ps=10006 17 (accessed 12 Jan 2010).

3. Bethell HJ, Lewin RJ, Dalal HM. Cardiac rehabilitation: it works so why isn't it done? Br J Gen Pract 2008; 58(555): 677-679.

4. National Institute for Health and Clinical Excellence. MI: secondary prevention in primary and secondary care for patients following a myocardial infarction. Clinical guideline 48. London: NICE, 2007. http://www.nice.org.uk/nicemedia/pdf/CG48NICEGuidance.pdf (accessed 29 Apr 2010).

5. Department of Health. National Service Framework for coronary hear disease. London: Department of Health, 2000.

6. Dalal HM, Evans PH, Campbell JL, et al. Home-based versus hospital-based rehabilitation following myocardial infarction: A randomized controlled trial with preference arms - Cornwall Heart Attack Rehabilitation Management Study. Int J Cardiol 2007; 119(2): 202-211.
7. Jolly K, Lip GYH, Taylor RS, et al. The Birmingham rehabilitation uptake maximisation study (BRUM): a randomised controlled tria comparing home-based with centre-based cardiac rehabilitation. Heart 2009; 95(1): 36-42.

8. Beswick AD, Rees K, Griebsch I, et al. Provision, uptake and cost of cardiac rehabilitation programmes: improving services to underrepresented groups. Health Technol Assess 2004; 8(41): iii-iv, ix-x, $1-152$.

9. Brodie D, Bethell H, Breen S. Cardiac rehabilitation in England: a detailed national survey. Eur J Cardiovasc Prev Rehabil 2006; 13(1): 122-128.

10. Dalal HM, Evans PH. Achieving national service framework standards for cardiac rehabilitation and secondary prevention. BMJ 2003; 326(7387): 481-484.

11. Fox KA, Birkhead J, Wilcox R, et al. British Cardiac Society Working Group on the definition of myocardial infarction. Heart 2004; 90(6): 603-609.

12. Valenti L, Lim L, Heller RF, Knapp J. An improved questionnaire for assessing quality of life after acute myocardial infarction. Qual Life Res 1996; 5(1): 151-161.

13. Jackson L, Leclerc J, Erskine, Linden W. Getting the most out of cardiac rehabilitation: a review of referral and adherence predictors. Heart 2005; 91(1): 10-14.

14. Cortes O, Artyhur HM. Determinant of referral to cardiac rehabilitation programs in patients with coronary heart disease: a systematic review. Am Heart J 2006; 151(2): 251-256.

15. Riley DL, Krepostman S, Stewarrt DE, et al. A mixed methods study of continuity of care from cardiac rehabilitation to primary care physicians. Can J Cardiol 2009; 25(6): e187-e192.

16. CREST (Clinical Resource Efficiency Support Team). Guidelines for Cardiac Rehabilitation in Northern Ireland. Belfast: Department of Health and Social Services and Public Safety, 2006.

17. McCorry NK, Corrigan M, Tully MA, et al. Perceptions of exercise among people who have not attended cardiac rehabilitation following myocardial infarction. J Health Psychol 2009; 14(7): 924-932.

18. Cooper AF, Jackson G, Weinman J, Horne R. Factors associated with cardiac rehabilitation attendance: a systematic review of the literature. Clin Rehabil 2002; 16(5): 541-545.

19. Clark AM, Hartling L, Vandermeer B, McAlister FA. Meta-analysis: secondary prevention programs for patients with coronary artery disease. Ann Intern Med 2005; 143(9): 659-672.

20. Jolliffe JA, Rees K, Taylor RS, et al. Exercise-based rehabilitation for coronary heart disease (Cochrane Review). Cochrane Database Syst Rev 2001; (1): CD001800.

21. Cupples ME, McKnight A. Randomised controlled trial of health promotion in general practice for patients at high cardiovascular risk. BMJ 1994; 30(6960): 993-996.

22. Campbell NC, Ritchie LD, Thain J, et al. Secondary prevention in coronary heart disease: a randomized trial of nurse led clinics in primary care. Heart 1998; 80(5): 447-452.

23. Campbell SM, Roland MO, Middleton E, Reeves D. Improvements in quality of clinical care in English general practice 1998-2003: longitudinal observational study. BMJ 2005; 331(7525): 1121-1125.

24. Cupples ME, Byrne MC, Smith SM, et al. Secondary prevention of cardiovascular disease in different primary healthcare systems with and without pay-for-performance. Heart 2008; 94(12): 1594-1600. 